\title{
$\mathrm{PE}$ 계열 절연재 전기적 특성 평가
}

\section{Electrical Characteristics Assessment for PE Series Insulations}

\author{
정종욱 ${ }^{1, a}$, 정진수 ${ }^{1}$, 한운기 ${ }^{1}$ \\ (Jong-Wook Jung ${ }^{1, a}$, Jin-Soo Jung', and Woon-Ki Han')
}

\begin{abstract}
This paper describes the results of electrical characteristics assessment for organic insulations of polyethylene(PE) series insulations and acrylonitrile butadiene styrene copolymer(ABS). In the experiment, 4 kinds of specimens by composition density were tested in relative permittivity, specific resistance and tracking duration. A WinDETA system and a tracking test set manufactured for this assessment were used to measure the dielectric parameters and tracking duration, respectively. In measuring the tracking duration, the time from testing voltage application to testing circuit breaking due to the tracking current was measured. As a result, dielectric dispersion was observed in measuring the relative permittivity of $\mathrm{ABS}$. It was confirmed that the relative permittivity decreased with the density of the PE series insulations and it depends rather on the temperature than frequency. In most specimens, specific resistance exponentially decreased with frequency and the result for each specimen was almost similar. By the way, in the tracking test, all the PE series insulations showed more excellent performance than ABS and especially in the case of HDPE, its tracking withstand performance was the best.
\end{abstract}

Key Words : Electrical characteristics assessment, Polyethylene series insulations, Acrylonitrile butadiene styrene, Relative permittivity, Specific resistance, Tracking duration

\section{1. 서 론}

2010년까지 세계 충생산능력의 $20 \%$ 까지를 감 당하게 될 국내 $\mathrm{PE}$ (polyethylene) 산업은 재료의 응용범위가 날로 확대되고 있는 가운데 다양한 분 야에서 그 제반특성이 평가되어 왔으며, 이를 기저 수지로 하는 각종 컴파운드도 꾸준히 개발되어 왔 다[1].

$\mathrm{PE}$ 는 에틸렌 $\left(-\mathrm{CH}_{2}-\mathrm{CH}_{2}-\right)$ 의 고분자중합체인 열 가소성 플라스틱으로서 조성밀도에 따라 $\mathrm{HDPE}$, $\mathrm{MDPE}$ 및 $\mathrm{LDPE}$ 로 구분된다. $\mathrm{PE}$ 는 1933년 crystal $\mathrm{LDPE}$ 를 필두로 1943년 $\mathrm{HDPE}$, 1955년 MDPE가

1. 한국전기안전공사 전기안전연구원 설비안전연구그룹 (경기도 가평군 청평면 상천리 27)

a. Corresponding Author : phdjung@korea.com

접수일자 : 2007. 3. 5

1차 심사 : 2007. 4. 9

심사완료 : 2007. 4. 19
각각 개발되었으며, 일반적으로 다음과 같은 특성 을 갖는다[2].

- 기계적 작업성 우수

- 낮은 수증기 투과성

- 높은 가스 투과성

- 무독, 무미, 이취(지방족, 방향족 탄화수소)

- 가공 중 열분해

- 높은 자외선 투과성

- $\mathrm{MDPE}, \mathrm{HDPE}$ 경우, 가열 살균 불능

- $\mathrm{LDPE}$ 의 경우, oil에 불안정 등

본 논문에서는 제반 장점에 의해 현재 가전제품 용 고분자 절연재로 널리 이용되고 있는 $\mathrm{ABS}$ 와의 재료 내부적 전기물성을 비교·평가하기 위해, 각기 조성밀도를 달리 하는 4 종의 $\mathrm{PE}$ 계열 절연재의 비 유전율과 고유저항을 측정하였다. 또한, 습기가 존 
재하는 전원설비의 충전된 단자 간에는 트래킹이 발생할 가능성이 있으며, 이는 절연재의 절연성능 이외에도 환경적 조건에 따라 그 발생특성이 판이 하게 달라지므로, 본 논문에서는 재료 외부적 전기 내성을 평가하기 위해 경사법을 사용하여 지속시 간을 측정·비교하고 실험 후의 표면 손상상태를 관찰하였다.

\section{2. 실 험}

각 시료의 비유전율과 고유저항을 측정하기 위 해 Novocontrol사의 WinDETA를 이용하였으며, 트래킹 성능 평가를 위해 별도의 장치를 구성하였 다. 실험에 사용한 장치들의 개략도 및 실험절차를 이하에 각각 나타내고 설명하였다.

그림 1 에 보인 WinDETA는 온도와 주파수의 변화에 따른 제반 유전 파라미터를 자동으로 측정 하기 위한 장치로서 본 실험에서는 시료로 사용할 각 절연재 팰릿을 $0.18 \mathrm{~mm}$ 두께로 가공하여 직경 $20 \mathrm{~mm}$ 의 전극 간에 끼워 넣은 후 시료셀 내에 설 치하였다. 온도는 $\mathrm{PE}$ 계열 절연재의 실제 전기적 사용환경온도라고 간주되는 $-20{ }^{\circ} \mathrm{C}$ 부터 $100{ }^{\circ} \mathrm{C}$ 까 지의 범위에서 $5{ }^{\circ} \mathrm{C}$ 씩 증가시키면서 $10^{\circ} \mathrm{Hz}, 10^{2}$ $\mathrm{Hz}, 10^{4} \mathrm{~Hz}$ 및 $10^{6} \mathrm{~Hz}$ 에서의 비유전율과 고유저항 을 측정하였다.

한편, 그림 2(a)에 보인 바와 같이, 트래킹 시험 을 위한 기본회로는 크게 전원부, 시료부 및 도전 성 수용액 공급부로 구성되었다. 시료는 LLDPE, $\mathrm{LDPE}, \mathrm{MDPE}$ 및 $\mathrm{HDPE}$ 의 $\mathrm{PE}$ 계열 4종과 이와

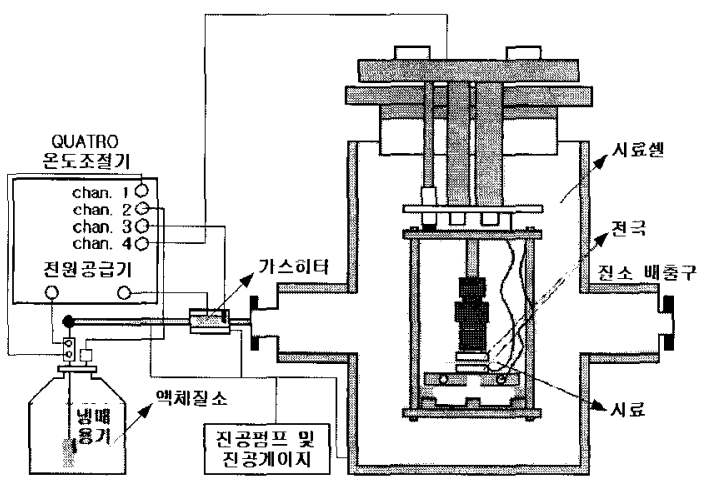

그림 1. 유전파라미터 측정에 사용된 WinDETA.

Fig. 1. WinDETA used for measuring dielectric parameters.

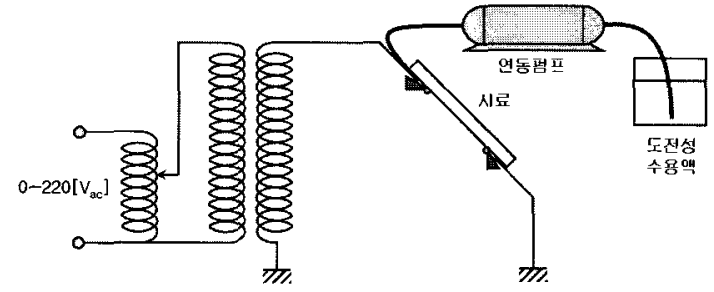

(a) 기본회로도

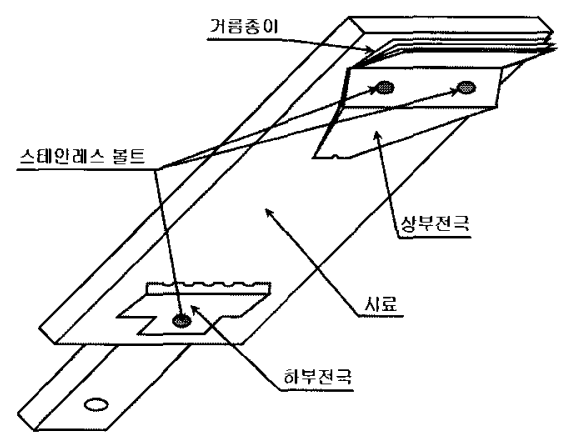

(b) 시료설치 부위

그림 2. 트래킹 시험장치 구성도.

Fig. 2. Electrical tracking test set.

비교하기 위한 $\mathrm{ABS}$ 를 사용하였으며, 핫프레스를 이용하여 팰릿형태의 각 시료를 $5 \mathrm{~mm}$ 두께로 가 공하였다. 이 시료를 다시 $50 \times 120 \mathrm{~mm}$ 의 크기로 재단한 후, 그림 2(b)와 같이, 재료 표면에 상부전 극과 하부전극을 $50 \mathrm{~mm}$ 이격하여 설치하고 상부 전극과 각 시료 간에는 도전성 수용액을 분당 3 $\mathrm{cc}$ 의 비율로 떨어뜨렸다. 이때 수용액이 재료 표면 에서 일정량을 유지하며 홀러내리도록 하기 위해 8 매의 거름종이를 재단하여 삽입한 후, 상부전극에 는 전원을 접속하고 하부전극은 접지하였다. 도전 성 수용액은 IEC 60112에서 제시한 바에 따라 플 라스크 내의 순수 $2 l$ 에 $0.1 \%$ 의 $\mathrm{NH}_{4} \mathrm{Cl}$, 음이온계 계면활성제인 $0.02 \%$ 의 Triton X-100을 넣고 교반 기로 고루 섞어 전체 수용액의 도전율이 $2,400 \mu \mathrm{S}$ 정도가 되도록 하였다[3]. 이와 같이 설치한 후, 도 전성 수용액이 재료 표면을 타고 흘러내리는 정도 가 균일해졌을 때, 두 전극 간에 $2.5 \mathrm{kV}_{\mathrm{ac}}$ 를 인가 하고 재료 표면에 흐르는 누설전류의 크기가 40 $\mathrm{mA}$ 일 때 전원이 차단되도록 세팅한 후, 전압 인가 시부터 차단 시까지의 시간을 측정하고 이 때 각 시료의 표면상태를 관찰하였다. 이와 같은 실험을 시료마다 3 번씩 반복하여 측정한 후, 그 평균값을 취하였다. 


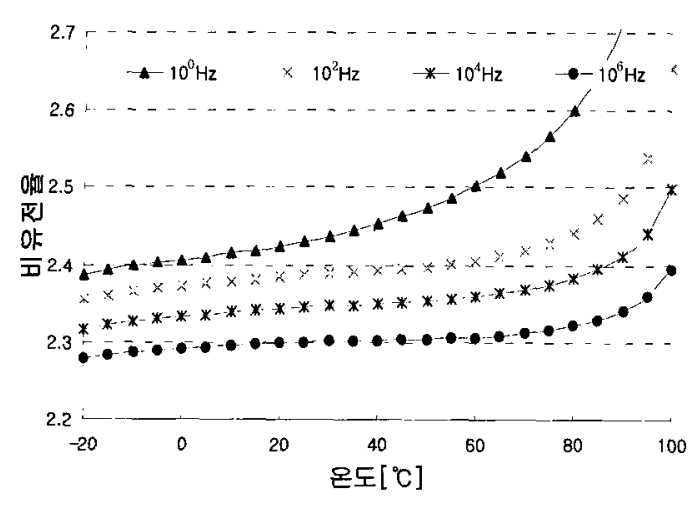

그림 3. $\mathrm{ABS}$ 의 비유전율.

Fig. 3. Relative permittivity of ABS.

\section{3. 결과 및 고찰}

\section{1 유전파라미터 측정 결과}

각 시료에 대해 비유전율을 측정한 결과, $\mathrm{PE}$ 계 열 절연재의 비유전율은 $\mathrm{ABS}$ 와 다른 양상을 띠고 있음을 알 수 있었으며, 우선 ABS의 비유전율을 그림 3 에 나타내었다.

그림 3에 보인 바와 같이, $\mathrm{ABS}$ 의 비유전율은 온도에 따라 전반적으로 증가하는 경향을 나타내 었으며, $23{ }^{\circ} \mathrm{C}, 10^{6} \mathrm{~Hz}$ 에서는 약 2.3 의 값을 나타내 었다. 그러나 주파수의 증가에 따라서는 오히려 감 소하였으며, 이는 절연재 내에서 발생하는 하나의 분극과정이 채 완료되기 전에 전계가 교번됨으로 인한 전형적인 유전분산현상으로서 분극의 형태는 영구쌍극자군이 전계방향으로 배향함에 의해 발생 하는 배향분극과 시료의 분균질성에 기인한 계면 분극이 주를 이루고 있다고 간주된다[4]. 이에 반 해 $\mathrm{PE}$ 계열의 절연재들은 $10^{6} \mathrm{~Hz}$ 까지의 비교적 낮 은 주파수 영역에서는 추파수에는 무관하게 온도 에 의해서만 비유전율이 변화하는 양상을 나타내 었다. 이 같은 경향은 4 종의 $\mathrm{PE}$ 모두에서 관찰되 었으며, 이 중 LDPE의 비유전율을 그림 4 에, 시료 의 밀도별 비유전율을 비교하여 그림 5 에 각각 나 타내었다.

그림 4에 보인 바와 같이, $\mathrm{LDPE}$ 의 비유전율은 온도에 따라 감소하는 경향을 나타내었으나, $10^{0}$ $\mathrm{Hz} \sim 10^{6} \mathrm{~Hz}$ 의 영역에서는 주파수에 따른 변화가 거의 없음을 알 수 있었다. 이는 $\mathrm{PE}$ 계열 절연재 에서 공통적으로 관찰되는 현상으로, 같은 열가소 성 수지이더라도 $\mathrm{ABS}$ 보다는 교번전계에 대한 쌍

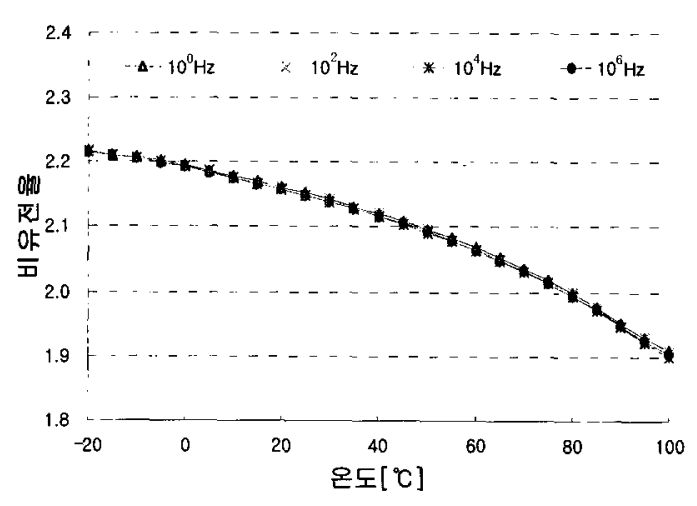

그림 4. $\mathrm{LDPE}$ 의 비유전율.

Fig. 4. Relative permittivity of LDPE.

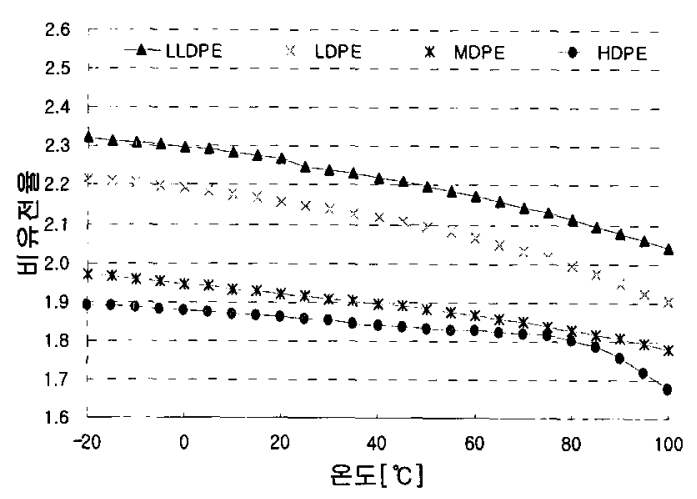

그림 5. $\mathrm{PE}$ 계열 절연재의 비유전율 비교.

Fig. 5. Comparison in permittivity of $\mathrm{PE}$ series insulations.

극자의 반응이 민감하게 이루어지기 때문이라고 사료된다. $\mathrm{PE}$ 계열 각 절연재들의 비유전율 중, $10^{6} \mathrm{~Hz}$ 에서 측정한 값만을 비교하여 그림 5 에 나 타내었다.

그림 5에 보인 바와 같이, $\mathrm{PE}$ 계열 절연재의 비 유전율은 LLDPE가 가장 높았으며, 재료의 조성밀 도에 따라 점차 감소하여 $\mathrm{HDPE}$ 에서 가장 낮은 값 을 나타내었다. 이는 단위공간 내에 속해있는 분자 수가 증가함으로 인한 상호간의 구속력이 비유전 율에 다소나마 영향을 주었기 때문이라고 사료 된다.

한편, 본 실험에서는 비유전율 이외에 재료의 고유저항을 측정하였으며, $\mathrm{ABS}$ 에 대한 결과를 그 림 6에 나타내었다. 


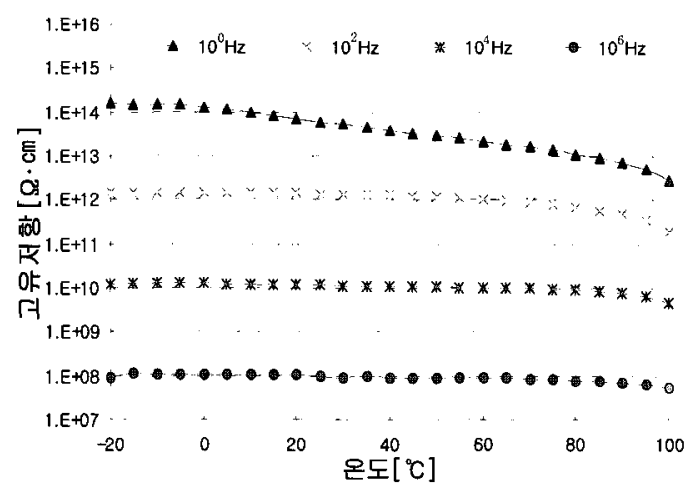

그림 6. $\mathrm{ABS}$ 의 고유저항.

Fig. 6. Specific resistance of $\mathrm{ABS}$.

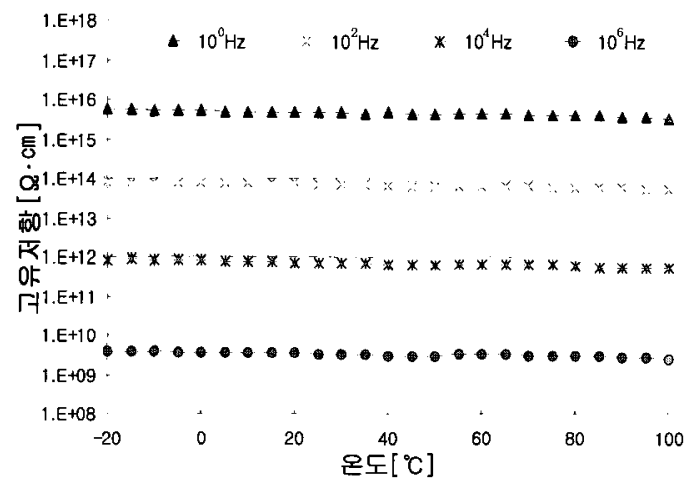

그림 7. LDPE의 고유저항.

Fig. 7. Specific resistance of LDPE.

그림 6 에 보인 바와 같이, $\mathrm{ABS}$ 의 고유저항은 주파수에 따라서는 지수적으로 감소하였으나, 온도 에 의한 영향은 저주파 영역을 제외하면 상대적으 로 적다는 것을 알 수 있었다. $\mathrm{PE}$ 계열의 절연재 에 대해서도 유사한 결과를 얻었으며, 이 중, $\mathrm{LDPE}$ 에 대한 결과만을 그림 7 에 나타내었다.

그림 7에 보인 바와 같이, $\mathrm{LDPE}$ 의 고유저항은 온도에 무관하게 일정한 값을 유지하였으며, 주파 수가 증가할수록 고유저항은 현저히 낮아지는 것 을 알 수 있었다. $\mathrm{PE}$ 계열 각 절연재의 $10^{6} \mathrm{~Hz}$ 에 서의 고유저항을 비교하여 그림 8에 나타내었다.

그림 8 에 보인 바와 같이, $\mathrm{PE}$ 계열 절연재의 고 유저항의 경우, 재료의 조성밀도에 따른 차이는 거 의 없었으나, $\mathrm{HDPE}$ 가 그중 높은 값을 나타내었다. 본 실험에서 사용된 $\mathrm{PE}$ 계열 절연재의 경우, 일례

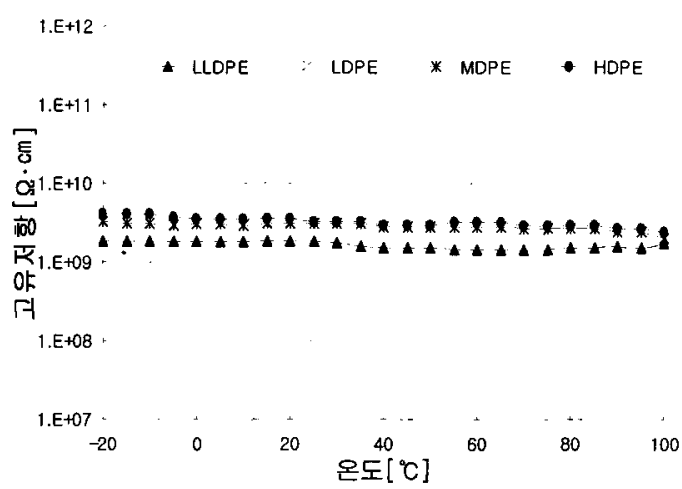

그림 8. $\mathrm{PE}$ 계열 절연재의 고윢저항 비교.

Fig. 8. Comparison in specific resistance of $\mathrm{PE}$ series insulations.

로 상용주파수인 $60 \mathrm{~Hz}$ 에서 $10^{14} \Omega \cdot \mathrm{cm}$ 내외의 고 유저항값을 나타내어 $\mathrm{ABS}$ 보다 월둥히 우수하다는 것을 알 수 있었으며, 온도에 따른 변화는 거의 없 었음이 확인되었다. 이는 고분자 블렌드의 경우 온 도에 의해 고유저항이 감소한다는 기존의 연구결 과와는 차이를 나타내는 것으로[5], 시료의 성분이 균질하여 혼합성분에 의한 영향이 없으므로 온도 에 따른 고유저항의 변화가 적기 때문이라고 생각 된다.

\section{2 트래킹 지속시간 측정 결과}

$\mathrm{PE}$ 계열의 고분자 절연재 및 $\mathrm{ABS}$ 시료에 전원 을 인가한 후 트래킹에 의한 누설전류로 전원이 차단되기까지 측정된 시간을 측정하여 그림 9 에 나타내었다.

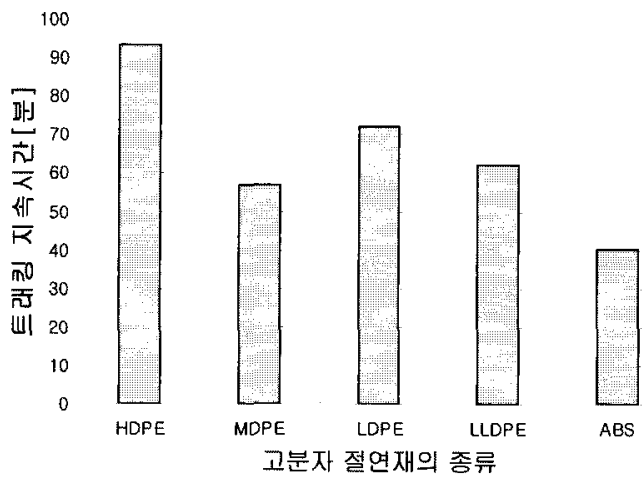

그림 9. 시료뼐 트래킹 지속시간.

Fig. 9. Tracking duration of specimens. 


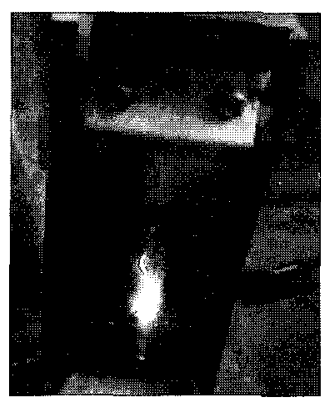

그림 10. 시료 상에 발생하는 트래킹.

Fig. 10. Electrical tracking on specimen surface.

그림 9에 보인 바와 같이, $\mathrm{PE}$ 계열의 고분자 절 연재 4종과 $\mathrm{ABS}$ 의 트래킹 지속시간을 측정한 결 과, $\mathrm{PE}$ 계열의 고분자 4 종은 대략 70 분 내외의 지 속시간을 나타내었던 반면, 현재 가전제품용 케이 스로 널리 사용되고 있는 $\mathrm{ABS}$ 는 $\mathrm{PE}$ 계열보다 짧 은 40 분 정도의 트래킹 지속시간을 나타내었다. 특 히, HDPE의 경우에는 90 분이 넘도록 트래킹이 지 속되어 트래킹에 대한 내성이 매우 우수함을 알 수 있었으며, 이는 HDPE가 LDPE에 비해 비교적 가지가 적고 결정성이 $85 \%$ 이상으로 표면의 굳 기, 강도가 높기 때문으로 사료된다[6]. 그림 10에 트래킹이 발생하는 순간을 촬영하여 나타내었다.

그립 10에 보인 바와 같이, 시료 표면에 연해 발생하는 트래킹의 발생경로는 표면을 타고 흐르 는 도전성 수용액의 경로를 따르는 경향도 일부 있으나, 일반적으로는 구불구불한 경로를 형성한 다. 이는 부분적으로는 트래킹 발생 메카니즘으로 설명할 수 있으며, 이를 그림 11에 나타내었다.

그림 11 과 같이, 가장 일반적인 메카니즘은 시 료 표면을 따라 진행하는 전자 캐스케이드나 2차 전자방출 애벌런치이다. 절연재, 전극 및 전자의 이동매질(공기 또는 도전성 수용액)이 이루는 삼중 점(triple junction)으로부터 전계방출된 전자의 일 부는 시료 표면에 충돌하여 2 차 전자를 방출한다. 이들 전자의 일부는 시료 표면에 재차 충돌하면서 3 차 전자롤 발생시킨다. 이 과정이 지속되면 2차 전자방출 애벌런치로 방전하는 시료 표면을 따라 캐스케이드가 발생한다[7]. 트래킹이라 함은 2 차 전자방출 애벌런치가 절연파괴까지 완전히 진행한 경우이다. 따라서, 전압의 크기, 수용액의 도전율 및 시료 표면의 오손도 이외에도 시료의 전자방출 특성 등이 트래킹의 경로 형성에 영향을 줄 수 있 다. 본 실험에 사용한 $\mathrm{PE}$ 계열의 절연재는 트래킹 의 지속적인 발생으로 인해 표면이 열화되고 누설 전류의 정도가 일정치에 이르러 전원이 차단된 후

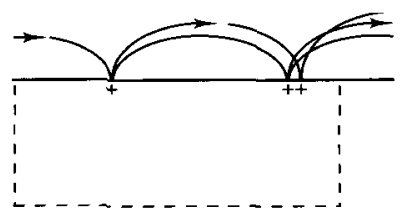

(a) 2차 전자방출 애벌런치

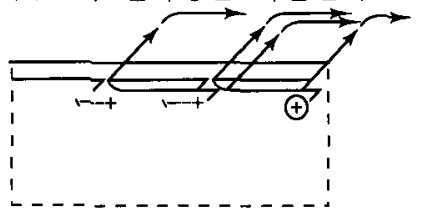

(b) 시료 내 전자 캐스케이드

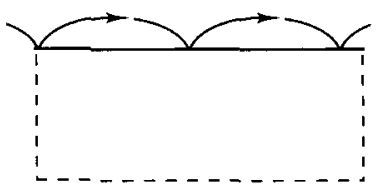

(c) 시료 표면의 전자충돌. 애벌런치 없음.

그림 11. 트래킹 발생 메카니즘.

Fig. 11. Tracking mechanism.

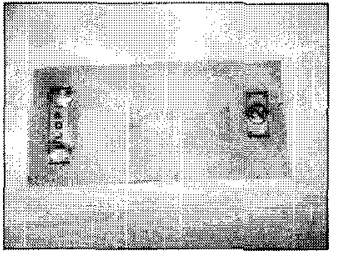

(a) LLDPE

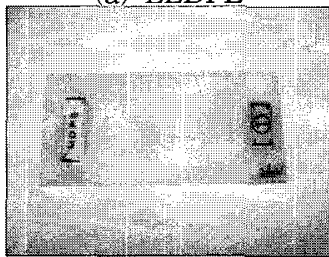

(c) MDPE

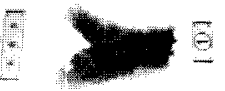

(e) ABS

그림 12. 트래킹 열화된 시로별 표면상태.

Fig. 12. Surface of tracking aged specimens.

표면상태를 관찰한 결과 대부분의 시로에서 탄화 흔을 발견할 수 없었으며, $\mathrm{ABS}$ 에서만 진한 탄화흔 을 발견하였다. 이 결과를 그림 12 에 나타내었다. 


\section{4. 결 론}

본 논문은 수분에 대한 특성이 다른 절연재에 비해 비교적 양호한 $\mathrm{PE}$ 계열의 재료에 대해 현장 적용을 위한 시작품을 제작하기 위한 재료 선택에 앞서 밀도가 서로 다른 $\mathrm{PE}$ 계열의 절연재 4 종에 대한 유전특성과 트래킹 내성을 측정하여 $\mathrm{ABS}$ 와 비교함으로써 전기적인 특성을 비교-분석하였다. 실험 결과, $\mathrm{ABS}$ 의 비유전율 측정 과정에서 유전분 산을 관찰할 수 있었다. $\mathrm{PE}$ 계열의 절연재는 밀도 가 높을수록 유전율이 낮아지는 것을 알 수 있었 으며, 주파수에 무관하게 온도에 따라서만 비유전 율이 감소하였다. 고유저항은 대부분의 시료에서 주파수가 증가할수록 현격히 감소하는 경향을 나 타내었으며, 시료별 큰 차이를 나타내지는 않았다. 이는 본 실험에 사용된 절연재가 균질재료이기 때 문이며, 혼합된 성분이 증가할수록 온도에 의한 영 향도 증가할 것으로 생각된다. 한편, 트래킹 내성 시험 결과, 모든 $\mathrm{PE}$ 계열 절연재가 $\mathrm{ABS}$ 보다는 높 은 특성을 나타내었으며, 특히 HDPE의 경우에는 타 절연재보다 월등히 우수한 결과를 나타내었다. $\mathrm{PE}$ 계열의 고분자는 일반적으로 수증기 투과성이 낮다는 점까지 고려하면 습기가 존재하는 장소에 $\mathrm{HDPE}$ 를 적절히 적용하기 위한 방안도 보다 깊이 있는 연구를 통해 강구되어야 할 것이다.

\section{감사의 글}

본 연구는 산업자원부 전력산업연구개발사업의 재정적 지원에 의해 수행되었으며, 이에 감사드립 니다.

\section{참고 문헌}

[1] 임지수, "한국 석유화학 산업, 깨져야 할 고정 관념 세 가지”, LG주간경제, 902호, 2006.

[2] "플라스틱 해설과 물성집", 한국플라스틱기술정 보센터 편집부, 한국플라스틱기술정보센터, 2006.

[3] Method for determining the comparative and the proof tracking indices of solid insulating materials under moist conditions, Internation al Electrotechnical Commission(IEC) 60112.

[4] 조정수, 이규철, 이종호, "전기전자 물성공학", 부산대학교 출판부, p. 368, 1992.

[5] 신종열, 이충호, 홍진웅, "혼합비에 따른 선형저 밀도폴리에틸렌과 에틸렌비널아세태이트 블랜 드의 전기적 특성”, 전기전자재료학회논문지, 14권, 6호, p. 525, 2001.

[6] 박승국, "폴리에 틸 렌수지", 대광서림, 1999.

[7] H. Craig Miller, "Surface flashover of insul ator", IEEE Trans. Electrical Insulation, Vol. EI-24, No. 5, p. 765, 1989. 